ISSN: 2578-3335 (Print) 2578-3343 (Online)

Volume 1 | Issue 1

Article 6

2019

\title{
Where have All the Female MD, PhD Applicants Gone?
}

Kathryn Behling

behling@rowan.edu

Cooper Rowan Medical Journal: https://rdw.rowan.edu/crjcsm

Would you like to be a reviewer? Please fill in this short form to express your interest.

\section{Recommended Citation}

Behling, Kathryn (2019) "Where have All the Female MD, PhD Applicants Gone?," Cooper Rowan Medical Journal: Vol. 1 : Iss. 1 , Article 6.

DOI: 10.31986/issn.2578-3343_vol1iss1.6

Available at: https://rdw.rowan.edu/crjcsm/vol1/iss1/6

\section{(c) (7)}

This work is licensed under a Creative Commons Attribution 4.0 License.

This Editorials and Letters to the Editor is brought to you for free and open access by the Rowan University Journals at Rowan Digital Works. It has been accepted for inclusion in Cooper Rowan Medical Journal by an authorized editor of Rowan Digital Works. For more information, please contact brush@rowan.edu. 


\section{Where have All the Female MD, PhD Applicants Gone?}




\title{
Where have All the Female MD, PhD Applicants Gone?
}

\author{
Kathryn Behling, ${ }^{1,2 *}$ \\ ${ }^{1}$ Department of Biomedical Sciences, Cooper Medical School of Rowan University, 401 Broadway, \\ Camden, 08103, NJ, USA \\ ${ }^{2}$ Pathology and Laboratory Medicine, Cooper University Hospital, 1 Cooper Plaza, Camden, 08103, NJ, \\ USA \\ *Corresponding author: behling@ rowan.edu (Kathryn Behling)
}

As has been observed by many, including Harrington et al. in this issue of Cooper Rowan Medical Journal, women continue to be underrepresented in the higher ranks of academic medicine as well as amongst physician-scientists. The cause of this disparity has been studied for many years. Indeed, as a bright-eyed, Medical Scientist Training Program (MSTP) student a little over 20 years ago, I attended several seminars, lunchtime talks, and lectures regarding this very subject. Sadly, the questions were the same as they are now, "Why do we have equal or even greater numbers of women entering medical school and $\mathrm{PhD}$ programs, but yet they are underrepresented at the higher ranks?" further emphasizing the persistence of this issue despite ample recognition and generous discussion. It is not that female candidates for $\mathrm{MD}, \mathrm{PhD}$ programs are less prepared, less interested in research or leave programs at a higher rate ${ }^{1}$, but rather that less of them apply ${ }^{2}$. As a young MD, PhD student, it was upsetting to hear physicians and researchers, many years my senior, discuss these issues. Major contributing factors often identified included the lack of female mentors, a problem that continues to this day, and lack of aggressiveness in women as they try to climb the academic ladder. Many times, the "elephant in the room", i.e. the hurdle that many women face as the primary caregiver for children, was not discussed. At the time, I felt this was one of the most important factors as I watched childcare stymie even the most motivated women as they tried to advance their academic careers.

One solution offered was to pair students such as myself with successful, female, physician-scientist mentors so that we could see that a future as a physician-scientist leader was attainable. However, according to recent data, this intervention, although needed, may not substantially increase the number of women physician- scientists, as those already enrolled in $\mathrm{MD}, \mathrm{PhD}$ programs don't usually suffer inordinate attrition ${ }^{1}$, and the real issue, identified by Harrington et al., is successfully encouraging women 
to apply to $\mathrm{MD}, \mathrm{PhD}$ programs. Other interventions that I also saw included lunchtime all-women junior faculty sessions geared at helping female junior faculty navigate the academic environment, including bolstering of negotiation skills necessary for career advancement.

Consideration of the survey data presented by Harrington et al. and recent literature on this subject helped me identify three main factors that I feel hamper female student entrance into $\mathrm{MD}, \mathrm{PhD}$ training programs: 1) overall decreased confidence in academic ability sufficient to complete an $\mathrm{MD}, \mathrm{PhD}$ program;2) decreased awareness of $\mathrm{MD}, \mathrm{PhD}$ programs and necessary preparation to enter these programs; 3 ) perception that a career in academic medicine is too challenging/unobtainable.

To play devil's advocate for a moment, one might ask, why do we care that there are fewer women than men amongst the ranks of physician-scientists? Beyond the desire to create a workforce that mirrors the overall patient population, women also are over-represented in several fields of medicine such as pediatrics and internal medicine ${ }^{3}$. Decreased numbers of physician-scientists in these areas could significantly hamper medical advances in these fields ${ }^{4}$. Additionally, physician-scientist training programs are important contributors to medical research beyond increasing the number of researchers. Indeed, physicians who complete these programs often have a unique research perspective due to their training in both medicine and basic science research ${ }^{1}$.

So why do female undergraduates shy away from applying to $\mathrm{MD}, \mathrm{PhD}$ programs? Through their survey of female undergraduate students, Harrington et al. found that one of the top reasons for not applying was a perceived lack of competitiveness as an applicant. In another study, Bowen et al. found that the disparity between male and female MSTP applicants increases as the research rank of the school increases, while this difference is not seen with MD program applications ${ }^{2}$. However, Bowen et al. found that the female students were just as academically successful as the male students, regardless of the school 's rank ${ }^{2}$. The authors speculated that female applicants may focus on lower ranking programs due to lack of confidence in their academic abilities and encouragement by undergraduate institutions ${ }^{2}$.

Harrington et al. also found that female undergraduate students, in particular those from institutions with less research activity, had decreased awareness of $\mathrm{MD}, \mathrm{PhD}$ programs. Increased awareness can be achieved through better academic advisement, however, when this advice is not received from successful, female, physician-scientist, it might fall flat. It is easy for someone to say that " anything is possible if you put your mind to it.", but the realities of pursuing a career path that includes substantially more training and potentially less compensation in an atmosphere that some may see as unwelcoming, is daunting atbest. Additionally, once women complete an $\mathrm{MD}, \mathrm{PhD}$ program, what do they have to look forward to? In a commentary written by McCarthy, he states that women in academic medicine, on average, get smaller start up packages, have lower productivity, and are represented at higher ranks to a lesser extent as 
compared to $\mathrm{men}^{3}$. Cornfield et al. states that as junior faculty, female physician-scientists often face a forced choice between career and child rearing, student loan debt compounded by less compensation for research vs. clinical activities, tenure expectations of immediate productivity, and lack of adequate infrastructure and mentorship ${ }^{4}$. So beyond decreased awareness of MSTP programs and decreased confidence, potential female applicants are confronting a challenging career path that may be accompanied by lack of support and difficult personal choices.

As mentioned above, it is important to improve the representation of women amongst the ranks of physician-scientists, so what is the best way to accomplish this? Cornfield et al. suggest the following key solutions, “. . . (1) a respectful and family-friendly workplace that includes flexible work hours, promotion clocks, and family support policies; (2) responsibilities that promote a sense of fulfillment and success, with greater than $75 \%$ dedicated research time and complementary clinical work; (3) promotion tracks that recognize both individual and team-based science; and (4) mentorship that is diverse, multigenerational, and multidisciplinary." "It is interesting that these authors focus their suggested interventions on physician-scientists that have completed training rather than on those entering the pipeline.

Ultimately, fixing the pipeline for female applicants to $\mathrm{MD}, \mathrm{PhD}$ programs should involve a multi-pronged approach that involves all stages of physician-scientist training and career development. Focused, successful interventions at each stage will not only encourage more women to apply, train, and eventually engage in this career path but will also assist those already training to remain in the pipeline and ultimately succeed.

\section{REFERENCES}

1. MD-PhD training: looking back and looking forward. Acad Med. 2014;89(1):21-23.

2. Bowen C J, Kersbergen C J, Tang O, Cox A, Beach M C. Medical school research ranking is associated with gender inequality in MSTP application rates. BMC Med Educ. 2018;18(1):187-187.

3. Female doctors and scientists in US lag in faculty promotions and research funding, studies find. $B M J$. 2015;351:4947-4947.

4. Cornfield D N, Lane R, Abman S H. Creation and retention of the next generation of physician-scientists for child health research. JAMA. 2013;309(17):1781-1782. 